\title{
WASH in Selected Basic Schools and Possible Implications on Health and Academics: An Example of the Wa Municipality of Ghana, West Africa
}

\author{
Samuel Kojo Abanyie ${ }^{1, ~ *}$, Ebenezer Ebo Yahans Amuah ${ }^{2,}$, , Nang Biyogue Douti ${ }^{1}$, George Owusu ${ }^{1}$, \\ Charles Casmed Amadu ${ }^{3}$, Barikisu Alhassan ${ }^{4}$ \\ ${ }^{1}$ Department of Environmental Science, Clement Kubindiwo Tedam University of Technology and Applied Sciences, Navrongo, Ghana \\ ${ }^{2}$ Department of Environmental Science, Kwame Nkrumah University of Science and Technology, Kumasi, Ghana \\ ${ }^{3}$ Department of Earth Science, Lement KubindiwoTedam University of Technology and Applied Sciences, Navrongo, Ghana \\ ${ }^{4}$ Ghana Scout Association, Wa, Ghana
}

Email address:

samuelabanyie@yahoo.co.uk (S. K. Abanyie), amuahyahans@gmail.com (E. E. Y. Amuah), binado1@yahoo.fr (N. B. Douti), geeyaw@yahoo.co.uk (G. Owusu), casmed07@yahoo.com (C. C. Amadu), alhassanbariky.50@gmail.com (B. Alhassan)

${ }^{*}$ Corresponding author

To cite this article:

Samuel Kojo Abanyie, Ebenezer Ebo Yahans Amuah, Nang Biyogue Douti, George Owusu, Charles Casmed Amadu, Barikisu Alhassan. WASH in Selected Basic Schools and Possible Implications on Health and Academics: An Example of the Wa Municipality of Ghana, West Africa. American Journal of Environmental Science and Engineering. Vol. 5, No. 1, 2021, pp. 15-20. doi: 10.11648/j.ajese.20210501.13

Received: December 16, 2020; Accepted: December 30, 2020; Published: April 26, 2021

\begin{abstract}
Effective learning in school is significantly influenced by water, sanitation, and hygiene conditions. However, in most schools in developing countries, WASH is often inadequate. The study focused on the accessibility, availability, quality, and sufficiency of WASH in public schools. This cross-sectional study employed the use of an observational checklist where 29 self-administered questionnaires on WASH were administered to Headteachers of the selected schools. The study area was divided into six grids using ArcGIS 9.3@ , and from each grid, five schools were selected. However, in the northeastern part of the municipality four sample schools were chosen, since that area had fewer schools. The bacteriological quality (fecal coliforms) of water from the schools was assessed for health safety. The R software and Microsoft Excel were used for data analysis. The study showed that $37.9 \%$ of schools had access to potable water but $27.5 \%$ of these sources were fecally contaminated. Though $93.1 \%$ of the schools had toilet facilities, $77.8 \%$ were shared by both teachers and students. The study further showed that $96.6 \%$ were gender-segregated, $59.3 \%$ lacked toilet bins whiles $41.4 \%$ practiced open defecation. Hygiene facilities were lacking as $75.9 \%$ of the schools lacked hand washing facilities and all the schools lacked menstrual hygiene facilities. Solid waste and toilet facilities were poorly managed, contributing to open defecation in the schools. Generally, WASH in most of the schools was not satisfactory since they lacked facilities, policies, funds, sensitization, and proper maintenance. The study recommends that WASH facilities should be improved by all stakeholders.
\end{abstract}

Keywords: Water, Sanitation, Hygiene, Basic Schools, Health

\section{Introduction}

Safe and child-friendly water, sanitation, and hygiene (WASH) in schools contribute significantly to educational achievement, improve health, and promote gender equity and impact positively on communities United Nations Children's Fund (UNICEF) [1]. However, in most schools in developing countries, potable water and sanitation facilities, and hygiene education programs are often inadequate [2]. This exposes children to diarrhea and other related infections which increase school absenteeism and affect overall performance [3].

WASH is fundamental to the health and wellbeing of people [4]. Poor WASH influences morbidity and mortality [5]. About $85 \%$ of the preventable (diarrhea) diseases in Africa via water are caused by feco-oral contamination, and diarrheal diseases in children contribute to malnutrition and stunted growth [6] Lack of good drinking water, poor 
environmental management, poorly maintained latrines, and hand washing without soap contributes to the prevalence of diseases amongst children [3].

Graphic Online [7] and the Ghana News Agency in a reportage [8] indicated the lack of adequate and improved toilets in schools in northern Ghana, whereas a UNICEF [9] mentioned that most schools in Ghana have no Menstrual Hygiene Management (MHM) systems for female students which contributes to about $95 \%$ of schoolgirls missing school during menstruation. Poor MHM, lack of adequate, separated, and secured toilets, and washing facilities discourage parents from sending children (especially girls) to school [10]. It could further contribute to girls' absenteeism, school drop-out, and poor academic performance [3,11]. Although similar studies have been conducted globally, few of them have been done in Ghana, and most of these studies focused mainly on sanitation and hygiene in schools. However, this study couples the assessment of the quality, availability, accessibility, and sufficiency of water facilities, sanitary and hygienic conditions, and practices in selected basic schools within the Wa Municipality.

\section{Materials and Methods}

\subsection{Overview of the Study Area}

The Wa municipality lies within latitudes $9^{\circ} 32^{\prime}$ North and $10^{\circ} 20^{\prime}$ North, and longitudes $1^{\circ} 40^{\prime}$ West and $2^{\circ} 45^{\prime}$ West (Figure 1). It shares boundaries with the Nadowli, Tuna Kalba, Wa East, and Wa West Districts to the north, south, east, and west respectively [12]. It covers an area size of about $1,108 \mathrm{~km}^{2}$ with a population of 107,214 [13]. Though UNDP [13] reported that the municipality had 61 primary schools and 38 Junior High Schools as of 2008, this study identified 56 basic schools in the municipality. Basic school in Ghana comprises of Primary (class 1 to 6) and JHS.

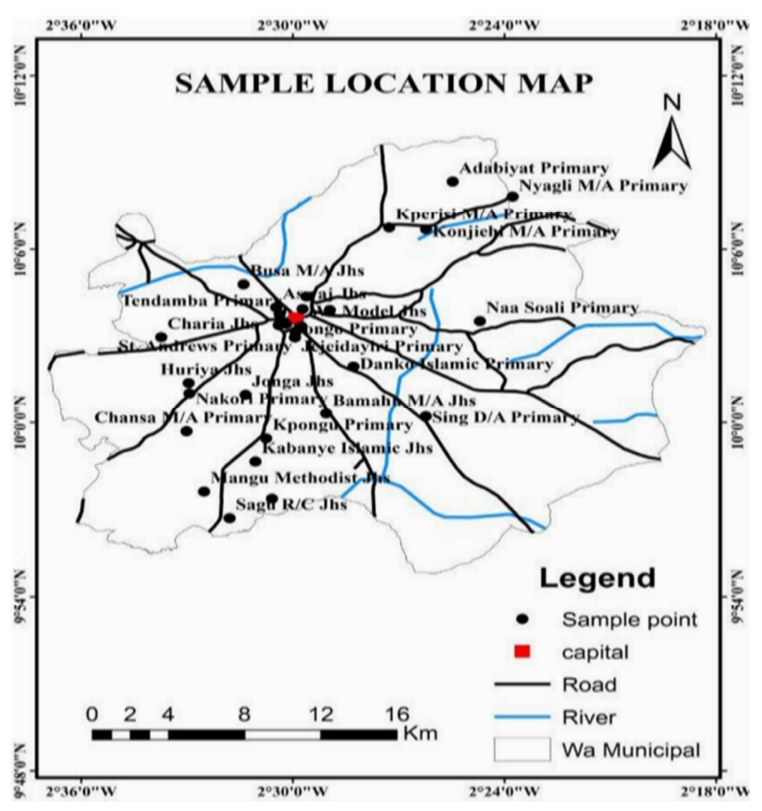

Figure 1. Location of sampled schools.

\subsection{Consent and Ethical Approval}

Before this study was conducted, permission was obtained from the Wa Municipal Education Directorate and the Headteachers of the sampled schools.

\subsection{Study Design and Sample Size Determination}

The study employed a cross-sectional study designed to assess the accessibility, availability, functionality, sufficiency, and quality of WASH facilities in selected public basic schools in the Wa municipality. The study population comprised of 56 public basic schools with a sample size of 29 basic schools which comprised 17 Primary and 12 Junior High Schools. The 29 schools were sampled using the sample size formula for a finite population following Cochran [14]:

$$
n=\frac{n_{o}}{1+\frac{n_{o}}{N}}
$$

Where;

$$
n_{0} \geq \frac{z^{2} \sigma^{2}}{d^{2}}
$$

The margin of error $(5 \%), 95 \%$ confidence level, standard deviation (0.2), and a $\mathrm{z}$ value of 1.96 were used. $N$ is the total number of schools (56), $d$ is the margin of error, $\sigma$ is the standard deviation, $n_{\mathrm{o}}$ is the initial sample size and $n$ is the sample size.

\subsection{Sampling Method and Study Instrument}

A multi-stage sampling technique was employed in this study. The municipality was divided into six grids using ArcGIS 9.3@ . From each grid, random sampling was used in selecting five sample schools, except for the northeastern part of the municipality where four sample schools were chosen since it had few schools. A purposive sampling method was used to select participants (preferably Headteachers) to complete a structured questionnaire. Also, interviews were conducted with teachers, and students for information on the accessibility to WASH facilities and their experiences regarding the facilities in their respective schools. A checklist that covered the availability and accessibility of potable water, the availability, cleanness, and adequacy of toilet facilities, and the mode of waste disposal were used in the assessment of water, sanitation, and hygiene of the various schools. Water samples were also collected from all the sampled schools with water supply systems for enteric bacteria load examination.

\subsection{Enteric Bacteria Load Analysis of Water Samples}

Bacteriological analysis was carried out on the water samples collected from the various schools to determine their quality and safety to health. Membrane Filtration using MFC (Tergitol) agar was adopted. Fecal coliform loads of the water samples were determined following the American Public Health Association [15]. 


\subsection{Statistical Analyses}

The garnered data from the administration of the questionnaires and semi-structured interviews were analyzed and interpreted using the $\mathrm{R}$ software (version 3.6.3) and Microsoft Excel (2016 version).

\section{Results and Discussion}

\subsection{Water Availability}

According to Butt [11], adequate and improved water supply is a key issue in WASH. However, the majority $(62.15 \%)$ of the schools lacked potable water (Figure 2). This indicated poor water availability. This was similar to the findings of UNICEF [16] where $43 \%$ of schools had water facilities. Schools with available water $(37.9 \%)$ had their supply from pipes $(36.4 \%)$ and boreholes (63.6\%) (Table 1). Similar to the findings of Olukanni [17] in Southwestern Nigeria, 20\% of schools had available water. Though the accessibility of water was inadequate, the majority of the schools relied on improved water sources. However, school-based water treatment and regular water quality analyses were not done to ascertain the suitability of the available water. The presence of fecal coliform in the water of $3(10.3 \%)$ of the schools was observed to have probably emanated from poorly washed receptacles used in fetching water and uncovered water which were easily reached by pupils. Also, fecal materials may have been carried through broken pipelines from the delivery source. Bacterial contamination of the groundwater may also be due to open defecation alike to the findings of Saana et al. [18] where fecal coliforms were detected in groundwater sources within the area. Considering the schools without pipe connections or boreholes, accessibility to water was observed to be within the WHO standard of $30 \mathrm{~m}$.

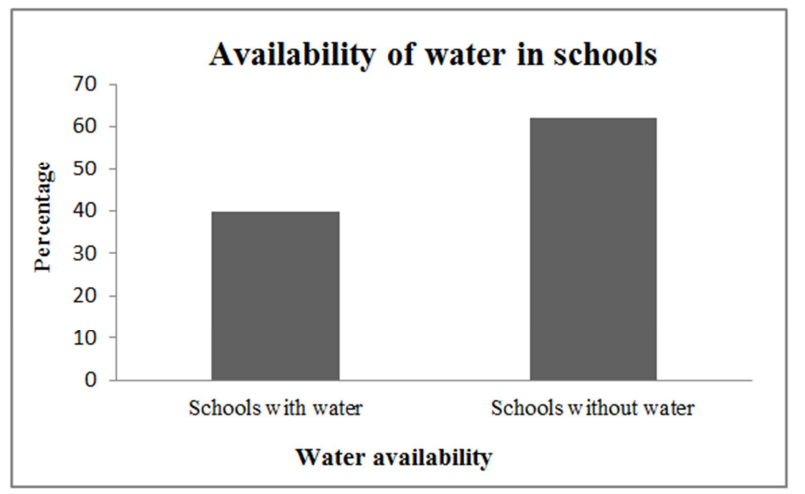

Figure 2. Water availability in schools.

Hand hygiene is a significant method to reduce illnessrelated diseases among school children by $26 \%$ [19]. The provision of water for 5 to 7 days in a week motivated hand washing at $7(63.64 \%)$ of the schools with water sources. However, $5(45.5 \%)$ of the schools had unfriendly water systems for children and physically challenged. This showed that the physical abilities of students and teachers were not considered in the engineering of schools' water supply systems. This may hamper disabled children from enrolling in schools, underuse/unused/ misuse of water projects.

Table 1. Sources of water in schools.

\begin{tabular}{lll}
\hline Water source & Frequency & Percentage \\
\hline Pipe & 4 & 36.4 \\
Borehole & 7 & 63.6 \\
Total & 11 & 100 \\
\hline
\end{tabular}

\subsection{Sanitation}

\subsubsection{Availability and States of Toilet Facilities}

Improved toilet sanitation positively imparts health and school attendance [20]. Though a majority of the schools (93.1\%) had toilets (Figure 3), 92.59\% of the toilets facilities were observed as unclean, and lacked proper maintenance (Table 2 and Figure 7). However, Koopman [21] mentioned that unhygienic toilet conditions particularly feces on the bowl was related to increased diarrhea prevalence. It is therefore essential that adequate toilet facilities are provided for schools as Migele et al. [22] discussed that the incidence rates of diarrheal diseases amongst pupils decreased after the installation of WASH facilities. Most of the toilets observed in the various schools lacked bins (Figure 7), some had cracks, leaking roofs, and had feces and urine on the floors. These lapses were observed to be a result of poor monitoring by the schools' management and sanitation personnel from the local government authority, poor education on how to use the toilet facilities, the lack of frequent cleaning, and illegal usage by nonstudents. Though the toilet facilities were within the schools' premises (and conformed to the WHO standard of $1 \mathrm{~km}), 2(7.40 \%)$ schools had raised slabs which made them inaccessible and uneasily used by younger and disabled students and teachers. Heat and flies within the toilets also discouraged the usage of these facilities, thus encouraging open defecation in 12 (41.4\%) schools. Another unhygienic behavior observed was indiscriminate waste disposal within school compounds. These practices were attributable to the lack of sensitization on the importance of using the toilets facilities, poor maintenance of toilet facilities, insufficient drop holes, and unsegregated toilets for students and teachers (Figure 5). Due to the absence of bins, students resorted to dropping used tissue papers into the toilet holes. This made toilet pits full before their estimated periods.

Table 2. The state and maintenance of toilet facilities in schools.

\begin{tabular}{lll}
\hline State of toilet & Frequency & Percentage \\
\hline Clean & 2 & 7.4 \\
Moderately clean & 9 & 33.3 \\
Not clean & 16 & 59.3 \\
Total & 27 & 100 \\
\hline & & \\
\hline Cleaning & Frequency & Percentage \\
\hline Daily & 6 & 22.2 \\
Once a week & 6 & 22.2 \\
Irregular & 15 & 55.6 \\
Total & 27 & 100 \\
\hline
\end{tabular}




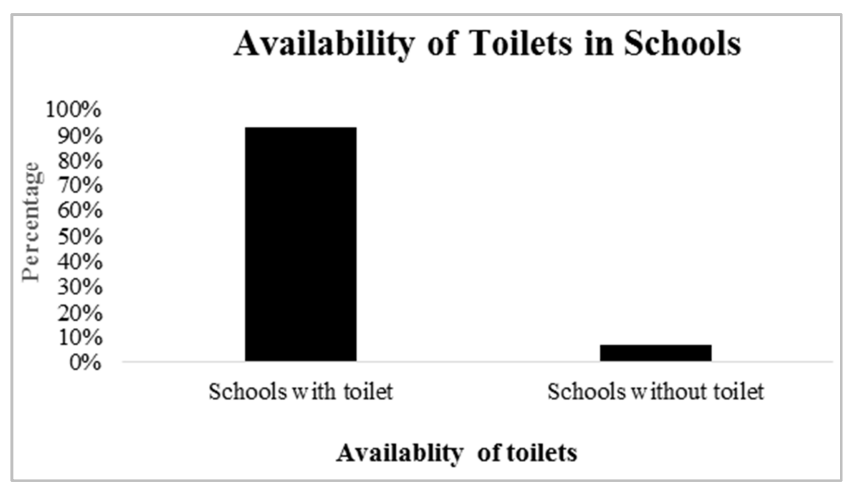

Figure 3. Availability of toilets in schools.

\subsubsection{Segregation of Toilets}

Though UNICEF recommends 25 girls and 50 boys to one drop-hole, in this study, $21(77.7 \%)$ schools flouted this standard. This placed pressure on the facilities, making management and maintenance difficult. Teachers were inconvenienced using toilets at school during school hours due to shared facilities with students (Table 3). This affected the performance of the teachers as they either resorted to using toilets in nearby houses or returned to their homes. Though $26(96.3 \%)$ of the schools had gender-segregated toilets (Figure 4), it was observed that the toilet facilities designated to female students were well maintained than those for males. This suggests that the female students were better informed in matters of hygiene. The lack of dustbins in $24(82.76 \%)$ of the schools (Table 4$)$ may be due to the minimal attention was given to solid waste disposal, as 12 (41.38\%) schools resorted to open dumping, 2 (6.9\%) buried waste and $15(51.72 \%)$ resorted to burning (Table 4$)$. These methods of waste disposal were practiced without careful consideration of the associated environmental and health implications. These practices were influenced by the lack of funds to subscribe to public waste collectors. Similar to Olukanni [17] in a study in Nigeria, all the schools did not have sanitation clubs to educate students on the essence of good sanitation. Finally, all the schools lacked signs and labels to direct and educate students on how to promote good sanitation at school. However, Karon et al. [23] observed that interventions geared towards improving WASH in schools increase student's communication about hygiene, improved student's knowledge of WASH, increased handwashing after defecation, and reduced open defecation at school.

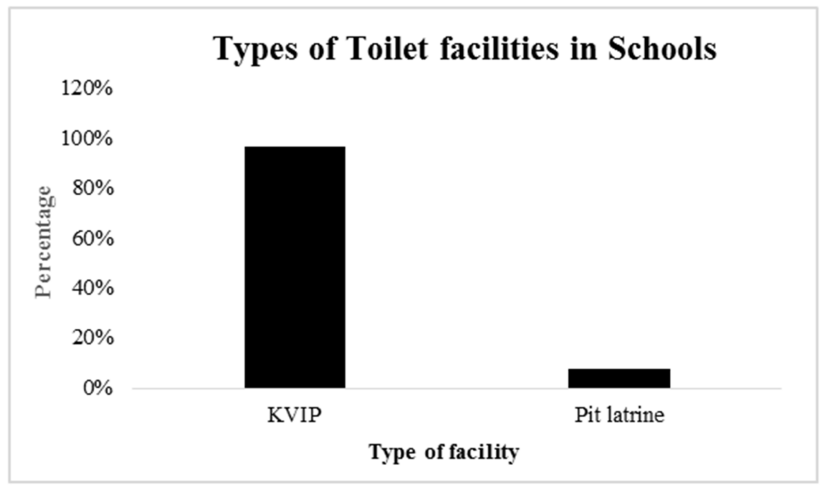

Figure 4. Toilet facilities in schools.

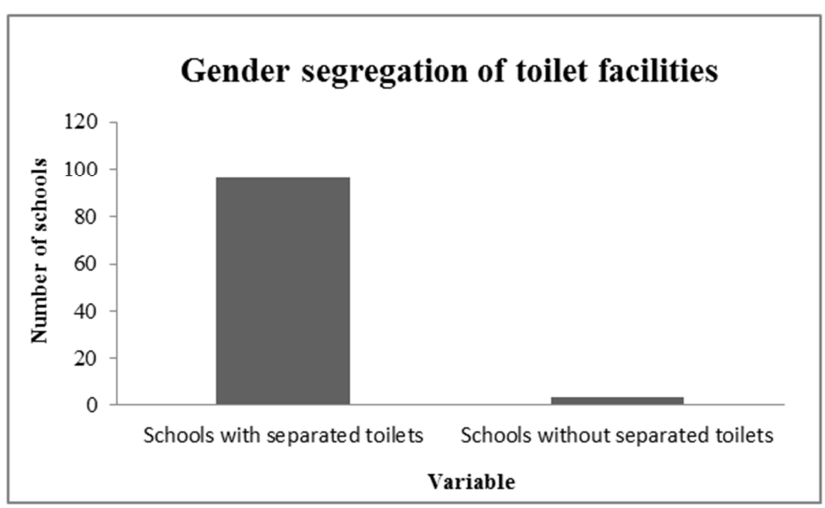

Figure 5. Gender segregation of toilets.

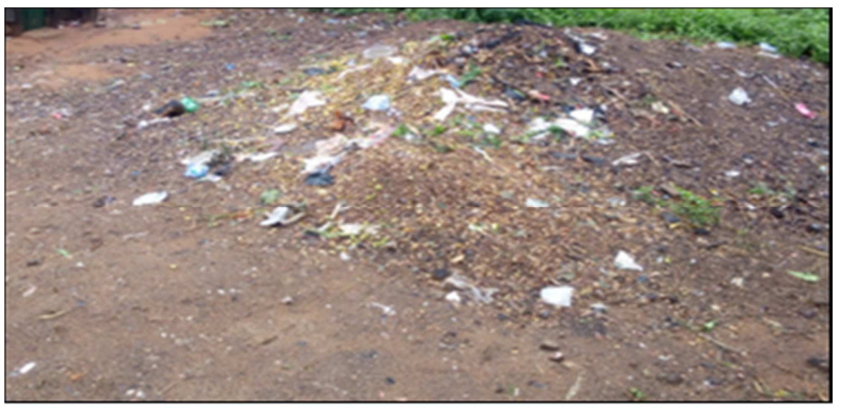

Figure 6. Waste disposal site at a school.

Table 3. Segregated toilets for Teachers and open defecation.

\begin{tabular}{|c|c|c|c|c|c|}
\hline Availability of toilets & Freq. & $\%$ & Open defecation & Number of schools & $\%$ \\
\hline Toilets for teachers & 6 & 22.2 & Yes & 12 & 44.4 \\
\hline No toilets for teachers & 21 & 77.8 & No & 15 & 55.6 \\
\hline Total & 27 & 100 & & 27 & 100 \\
\hline
\end{tabular}

Table 4. Availability of dustbins and forms of waste disposal in schools.

\begin{tabular}{|c|c|c|c|c|c|}
\hline Dustbins & Freq. & $\%$ & Waste disposal method & Freq. & $\%$ \\
\hline Available & 5 & 17.2 & Openly dumped & 12 & 41.4 \\
\hline Not available & 24 & 82.8 & Buried & 2 & 6.9 \\
\hline & & & Burnt & 15 & 51.7 \\
\hline Total & 29 & 100 & & 29 & 100 \\
\hline
\end{tabular}




\subsection{Hygiene}

The lack of adequate handwashing stations in 22 $(75.86 \%)$ schools (Table 5) and the lack of handwashing with soap in $8(28.6 \%)$ schools indicate that students and teachers were susceptible to wash-related diseases. Dreibelbis et al. [24] revealed that the provision of handwashing facilities potentially improves handwashing with soap among school children as handwashing increased a day after the facilities were provided and further increased to $74 \%$ at two and six weeks postintervention. Additionally, within 5 months of post WASH intervention, nudge intervention was equally effective at increasing proper handwashing with soap after toileting as mentioned by Grover et al. [25] and it significantly reduced days and student absenteeism [26]. Assefa and Kumie [19] in northern Ethiopia indicated that handwashing with soap protects children from diarrhea and lower respiratory infections which are the two most pediatric killers. It further reduces the occurrence of communicable diseases child morbidity and mortality in developing countries [27]. In this study, many of the students lack in-depth knowledge of the importance of frequent hand washing. Also, the schools did not engage in any sanitation-related activity. This may be attributed to the lack of handwashing facilities as Zormal [10] reported that the absence of handwashing facilities in schools negatively influenced handwashing behaviors.

The lack of MHM and sanitary materials showed that no deliberate support was given to female students, especially those who had experienced their menarche. This undermined female students' privacy and dignity and fuelled female absenteeism as some of the females either stayed away from schools or left school to wash and change their sanitary material during menstruation [28, 17]. Interestingly, in a pilot study in Ghana, Montgomery et al. [29] concluded that the provision of sanitary materials (pads) coupled with puberty education significantly increased school attendance. However, the studied schools lacked such materials. This hindered proper personal and public hygiene at school.

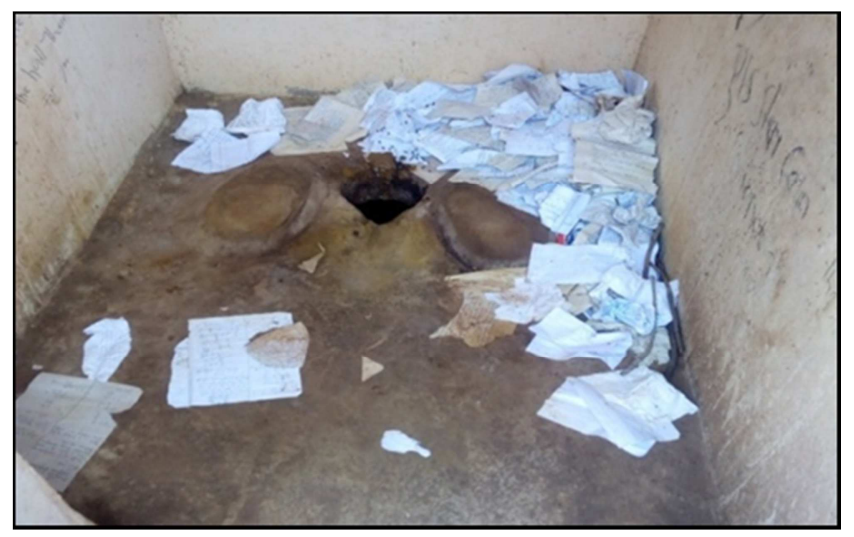

Figure 7. School toilet without a bin.
Table 5. The availability of handwashing facilities and soap.

\begin{tabular}{lll}
\hline Hand washing & Frequency & Percentage (\%) \\
\hline Schools with facilities & 7 & 24.1 \\
Schools without facilities & 22 & 75.9 \\
Total & 29 & 100 \\
Using soap & Frequency & Percentage (\%) \\
Schools with soap & 5 & 71.4 \\
Schools without soap & 2 & 28.6 \\
Total & 7 & 100 \\
\hline
\end{tabular}

\section{Conclusion and Recommendations}

To ensure a convenient environment for learning to improve school attendance and academic performance, WASH in schools must be a focal point for everyone. The WASH situation in public schools was generally poor. Toilet facilities were unkempt. Most of the schools lacked potable water, hand washing facilities, menstrual hygiene facilities and sanitary materials, well-segregated gender-based toilets, and proper waste management and disposal facilities. Some of the WASH facilities were unfriendly and inaccessible to younger and disabled students/teachers. It is recommended that; (1) WASH facilities should be improved by the government in schools in the Wa municipality; (2) WASH facilities should be provided/constructed considering the various guidelines for WASH to ensure that facilities are adequate, sufficient, accessible, and safe for use; and (3) the Ghana Education Service should imbibe sanitation education into the curriculum.

\section{Conflict of Interest}

The authors declare no conflict of interest.

\section{Acknowledgements}

The authors extend their gratitude to the Wa Municipal Education Directorate and the schools for permitting them to carry out this study.

\section{References}

[1] United Nations Children's Fund (UNICEF) (2010) Diarrhoea: why children are still dying and what can be done. [Online] http://www.unicef.org/media/files/Final_Diarrhoea_Report_O ctober_2009_final.pdf. Accessed Octobēr 1, 2020.

[2] United Nations Development Programme (UNDP) (2011) Human Development Report 2011. [Online] http//www.gh.undp.org/content/dam/Ghana/docs/Doc/IncIgro/ UNDP_GH_INCGRO_DHDR2011_Wa-MunicipalAssemb̄ly.p̄̄f Accessē November 11, 2020.

[3] Adams J, Bartram J, Chartier Y, Sims J. (Eds.) 2009 Water, sanitation and hygiene standards for schools in low-cost settings. World Health Organization.

[4] Abanyie S. K, Ampadu B, Saeed Z. M, Amuah E. E. Y, Douti N. B, Owusu G (2019) The roles of community-based water and sanitation management teams (WSMTs) for sustainable development: An example of the Bawku West District, Ghana. AJEST, 13 (11), 439-449. 
[5] World Health Organization (WHO) (2004) Water, Sanitation and hygiene links to health. [Online] https://www.who.int/water sanitation health/publications/fact s2004/en/ Accessed November 20, $20 \overline{2} 0$.

[6] Grossi V, Klimschak E, Rechenburg A, Shinee E, Schmoll O (2016) The situation of water, sanitation and hygiene in schools.

[7] Graphic Online (2014) Improving toilet facilities in schools. [Online]

https://www.graphic.com.gh/features/features/improvingtoilet-facilities-in-schools.html Accessed December 5, 2020.

[8] Ghana News Agency (2018) N/R: Female Students Cry Over Few Toilet Facilities. [Online] https://newsghana.com.gh/n-rfemale-students-cry-over-few-toilet-facilities/ Accessed October 8, 2020.

[9] UNICEF (2016) Menstrual Hygiene. Challenges, Taboos and Impact on Girl's Education. Ghana Research Briefs - 2016. [Online]

http://www.wins4girls.org/resources/2017\%20Ghana\%20Men strual\%20Hygiene\%20in\%20Ghana\%20Research\%20Brief.pd f Accessed November 20, 2020.

[10] Zormal F (2016) School Sanitation, Hygiene and Coping Strategies Among Girls in Junior High Schools in the Wa Municipality. [Online] http://udsspace.uds.edu.gh/bitstream/123456789/1398/1/SCH OOL\%20SANITATION.pdf Accessed October 25, 2020.

[11] Butt N (2014) Evaluating Water, Sanitation and Hygiene (WASH) affecting school children performance in Lahore and Islamabad, Pakistan (Doctoral dissertation, Albert-LudwigsUniversität Freiburg).

[12] UNICEF (2011) Water, Sanitation and Hygiene (WASH) Annual Report 2010.2 [Online] https://www.unicef.org/publications/files/CFS_WASH_E_web .pdf Accessed on November 3, 2020.

[13] Osumanu I. K, Kosoe E A, Ategeeng F (2019) Determinants of Open Defecation in the Wa Municipality of Ghana: Empirical Findings Highlighting Sociocultural and Economic Dynamics among Households. JEPH, 2019.

[14] Cochran W. G (1963) Sampling Techniques, $2^{\text {nd }}$ Ed., New York: John Wiley and Sons, Inc.

[15] American Public Health Association (APHA) (1998) Standard Methods for the Examination of Water and Wastewater. $20^{\text {th }}$ ed. Washington D.C, Pp. 4-145 to 4-146.

[16] UNICEF (2012) WASH in Schools Ghana Country Profile. [Online]:

https://www.unicef.org/about/annualreport/files/Ghana COA R_2012.pdf Accessed December 2, 2020.

[17] Olukanni D. O (2013) Assessment of wash program in public secondary schools in South-Western Nigeria. ARPN J. Eng. Appl. Sci., 8 (3), 222.

[18] Saana S. B. B. M, Fosu S. A, Sebiawu G. E, Jackson N, Karikari T (2016) Assessment of the quality of groundwater from drinking purposes in the Upper West and Northern Regions of Ghana. Springer Plus, 5 (1), 2001.

[19] Assefa M, Kumie A (2014) Assessment of factors influencing hygiene behaviour among school children in Mereb-Leke District, Northern Ethiopia: a cross-sectional study. $B M C$ Public Health, 14 (1), 1000.

[20] Moe C. L, Rheingans R. D (2006) Global challenges in water, sanitation and health. Journal of water and health, 4 (S1), 4157.

[21] Koopman J. S (1978) Diarrhea and school toilet hygiene in Cali, Colombia. Am. J. Epidemiol, 107, 412-420.

[22] Migele J, Ombeki S, Ayalo M, Biggerstaff M, Quick R (2007) Diarrhea prevention in a Kenyan school through the use of a simple safe water and hygiene intervention. Int. J. Epidemiol., 76 (2), 351-353.

[23] Karon A J, Cronin A, Cronk R, Henrdwan R (2017) Improving water, sanitation, and hygiene in schools inIndonesia: A crosssectional assessment on sustaining infrastructural and behavioral interventions. Int. J. Hyg. Environ. Health, 220, 539-550.

[24] Dreibelbis R, Kroeger A, Hossain K, Venkatesh M, Ram P (2016) Behavior Change without Behavior Change Communication: Nudging Handwashing among Primary School Students in Bangladesh. Int. J. Environ. Res. Public Health, 13, 129.

[25] Grover E, Hossain M. K, Uddin S, Venkatesh M, Ram P. K, Dreibelbis R (2018) Comparing the behavioural impact of a nudge-based handwashing intervention to high-intensity hygiene education: A cluster-randomised trial in rural Bangladesh. Trop. Med. Int. Health, 23, 10-25.

[26] Bowen A, Ma H, Ou J, Billhimer W, Long T, Mintz E,... Luby S (2007) A cluster-randomized controlled trial evaluating the effect of a handwashing-promotion program in Chinese primary schools. AJTMH, 76 (6), 1166-1173.

[27] Burns J, Maughan-Brown B, Mouzinho Â (2018) Washing with hope: evidence of improved handwashing among children in South Africa from a pilot study of a novel soap technology. BMC public health, 18 (1), 709.

[28] Oster E, Thornton R (2009) Menstruation and education in Nepal (No. w14853). National Bureau of Economic Research.

[29] Montgomery P, Ryus C. R, Dolan C. S., Dopson, S, Scott L. M (2012) Sanitary pad interventions for girls' education in Ghana: a pilot study. PloS one, 7 (10), e48274. 